\title{
INFLUÊNCIA DA RESISTÊNCIA E DO PERÍODO DE MOLHAMENTO NA INFECÇÃO E DESENVOLVIMENTO DE LESÕES DE FERRUGEM NO FEIJOEIRO
}

\author{
SIMONE R. SILVA, GERSON P. RIOS \& SILVANDO C. SILVA
}

\author{
Embrapa Arroz e Feijão, Cx. Postal 179, CEP 75375-000, Santo Antônio de Goiás, GO, \\ fax: (062) 533-2100, e-mail: gerson@cnpaf.embrapa.br.
}

(Aceito para publicação em 02/02/2001)

Autor para correspondência: Gerson Pereira Rios

SILVA, S.R., RIOS, G.P. \& SILVA, S.C. Influência da resistência e do período de molhamento na infecção e desenvolvimento de lesões de ferrugem no feijoeiro. Fitopatologia Brasileira 26:726-731. 2001.

\section{RESUMO}

Foram conduzidos experimentos visa ndo estudar a influência da resistência genética e do período de molhamento na infecção e desenvolvimento das lesões de ferrugem no feijoeiro (Phaseolus vulgaris). Cultivares suscetíveis, com resistência moderada e resistentes, após serem inoculadas com Uromyces appendiculatus, foram submetidas a períodos de $4,8,12,1620$ e $24 \mathrm{~h}$ de molhamento e levadas à uma câmara com regime de luz/escuro de $12 \mathrm{~h}$, temperatura de $22 \pm 1{ }^{\circ} \mathrm{C}$ e umidade relativa entre $70 \%$ e $80 \%$. Houve influência da resistência genética e do período de molhamento na infecção e desenvolvimento das lesões. As cultivares suscetíveis tiveram área foliar infetada e número de lesões crescentes até $20 \mathrm{~h}$, e $24 \mathrm{~h}$ de molhamento, respectivamente. As cultivares com resistência moderada apresentaram área foliar infetada e número de lesões crescentes até $24 \mathrm{~h}$ de molhamento. As diferenças entre períodos de 16, 20 e $24 \mathrm{~h}$ de molhamento quanto à área foliar infetada ou número de lesões $/ \mathrm{cm}^{2}$, não foram significativas. Um período de molhamento de $16 \mathrm{~h}$, sob temperatura de $22 \pm 1{ }^{\circ} \mathrm{C}$, pode ser suficiente para avaliar resistência à ferrugem no feijoeiro. Os períodos de incubação e de latência foram mais longos nas cultivares com resistência moderada que nas suscetíveis enquanto as porcentagens de lesões esporulantes e de suscetibilidade diferenciaram melhor as cultivares suscetíveis das moderadamente resistentes. O aprimoramento nas técnicas de avaliação da resistência genética à ferrugem do feijoeiro, e a adequação dos fatores de ambiente onde se desenvolve a pesquisa à epidemiologia .da doença, aumentará o alcance das informações obtidas.

Palavras-chave adicionais: pústulas, lesões esporulantes, lesões de suscetibilidade, período de incubação, período de latência, resistência moderada.

\section{ABSTRACT \\ Influence of genetic resistance and wetness period on infection and lesion development of common bean rust}

Two experiments were conducted to evaluate the influence of genetic resistance and wetness period on the infection and lesion development of common bean (Phaseolus vulgaris) rust. Susceptible, moderately resistant and resistant cultivars were subjected to $4,8,12,16,20$ and $24 \mathrm{~h}$ of wetness periods after inoculation with Uromyces appendiculatus. The experiment was conducted in a growth chamber with $12 \mathrm{~h}$ light/dark period, $22 \pm 1{ }^{\circ} \mathrm{C}$ and relative humidity of 70 to $80 \%$. There were significant effects of genetic resistance and wetness periods on the pathogen infection and lesion development. Resistant cultivars did not presented lesions at any wetness period, while susceptible cultivars present an increased percentage of leaf area infected from 4 to $20 \mathrm{~h}$, with a small decrease at the $24 \mathrm{~h}$ of wetness period. In these cultivars, the number of lesions increased up to $24 \mathrm{~h}$ of wetness. Moderately resistant cultivars also presented increases in leaf area infected and in the number of lesions up to $24 \mathrm{~h}$ of leaf wetness. There was no significant effect of 16,20 , and $24 \mathrm{~h}$ wetness duration in relation to leaf area infected or lesions per $\mathrm{cm}^{2}$. A wetness period of $16 \mathrm{~h}$ with a temperature of $22 \pm 1^{\circ} \mathrm{C}$ was sufficient for rust level resistance evaluation in common bean. Moderately resistant cultivars presented longer incubation and latent periods than suscetible cultivars. The percentage of sporulative lesions and susceptible lesions criteria better separate the cultivars into susceptible, moderately resistant, and resistant groups.

\section{INTRODUÇÃO}

A umidade constitui-se num dos fatores mais importantes que influenciam no desenvolvimento das doenças das plantas. A umidade, medida em termos de quantidade e duração, é essencial para que haja infecção pela maioria dos fungos e bactérias, agentes causais de doenças. Segundo Jones (1986), entre os fatores de ambiente que influenciam as doenças de plantas, a umidade é, às vezes, o mais importante, seguido pela temperatura. 
Influência da resistência e do período de molhamento na infecção...

Webb \& Nutter (1997) encontraram um efeito significativo da duração do período de molhamento e da temperatura no desenvolvimento das pústulas da ferrugem (Uromyces striatus Schroet) em alfafa (Medicago sativa $\mathrm{L}$.). A freqüência da infecção (número de pústulas por área foliar) aumentou linearmente quando a duração do período de molhamento cresceu de 4 a 24 h após a inoculação. Os autores concluíram que os processos monocíclicos como, freqüência de infecção, período de latência e capacidade de esporulação, responderam de maneira diferente a condições específicas de temperatura e umidade. Os mesmos autores determinaram que os efeitos críticos tanto da temperatura como da duração do período de molhamento, na freqüência de infecção da ferrugem em alfafa, ocorrem durante as $24 \mathrm{~h}$ iniciais de molhamento, que se seguem à deposição dos uredosporos. Webb \& Nutter (1997) argumentaram que, embora não haja uma explicação biológica para o fato do aumento cumulativo do número de pústulas no tempo serem irregulares, é possível que aquelas que emergem mais cedo, possam ter o efeito de dificultar o aparecimento daquelas que resultam de infecções posteriores.

Muitos estudos têm demonstrado que a resposta da planta à infecção pelo patógeno, quando medida através de componentes da resistência como número e tamanho de lesões, área foliar infetada e produção de esporos, varia entre as cultivares, com diferentes níveis de resistência. Em experimentos conduzidos por Thakur et al. (1991), foi demonstrado que os efeitos da temperatura e da duração do período de molhamento em panículas de milheto [Pennisetum glaucum (L.) R. Br.] infetadas por Claviceps fusiformis Lov. foram mais evidentes em genótipos suscetíveis que em genótipos resistentes ou moderadamente resistentes. Turechek \& Stevenson (1998) demonstraram, através de análise logística de regressão, que a probabilidade de uma folha de nogueira (Juglans regia L.) ser infetada por Cladosporium caryigenum Ellis \& Laugh foi maior na cultivar suscetível, aumentando a probabilidade com o aumento do período de molhamento foliar. Segundo Parlevliet (1979), a resistência parcial é tipicamente quantificada através da freqüência de infecção, do período de latência, do tamanho da lesão e da produção de esporos.

A alta umidade relativa ou o molhamento foliar são essenciais ao fungo Uromyces appendiculatus Pers., porque juntamente com a virulência do patógeno e a suscetibilidade do hospedeiro, são os fatores que garantem o estabelecimento da doença. Nos estudos referentes à ferrugem do feijoeiro, têm-se submetido as plantas a diferentes períodos de molhamento após a inoculação (Harter, 1935; Davison \& Vaughan, 1963, 1964; Stavely, 1984; Mora et al., 1992; Faleiro et al., 1999). Devido no passado ter sido utilizado diferentes períodos de molhamento e temperaturas, sugerese a necessidade de padronização destes fatores para que resultados futuros de identificação de patótipos e estudos de resistência genética possam ser comparados.

Este trabalho teve como objetivo estudar os efeitos do período de molhamento e da resistência genética do feijoeiro comum na infecção por Uromyces appendiculatus medidos através do período de incubação, período de latência, área foliar infetada, número total de lesões (pústulas + lesões necróticas), porcentagens de pústulas e de pústulas de suscetibilidade (pústulas maiores que $0,3 \mathrm{~mm}$ ).

\section{MATERIAIS E MÉTODOS}

\section{Inoculações}

A população de uredosporos foi obtida nos campos experimentais da Embrapa Arroz e Feijão e multiplicada na cultivar suscetível, Rosinha G-2. Nos referidos campos experimentais estavam sendo cultivadas diferentes cultivares de feijoeiro comum, principalmente aquelas componentes dos Ensaios Regionais e Nacionais de Melhoramento. As plantas a serem inoculadas foram cultivadas em vasos de alumínio com capacidade de $2 \mathrm{Kg}$ (quatro plantas por vaso), com quatro repetições, (três vasos em cada repetição), em casa de vegetação. Utilizou-se para o cultivo das plantas, um latossolo vermelho escuro de textura argilosa, com a seguinte adubação/ $\mathrm{kg}$ de solo: $200 \mathrm{mg}$ de $\mathrm{P}$ na forma de superfosfato simples; $107 \mathrm{mg}$ de N, na forma de Sulfato de amônio $14 \mathrm{mg}$ de K, na forma de Cloreto de Potássio; $100 \mathrm{mg}$ de FTE-BR-12, como fonte de micronutrientes. Foi adotado um delineamento inteiramente casualisado, disposto em parcelas subdivididas, sendo as parcelas representadas pelas cultivares e as subparcelas pelos períodos de molhamento. As inoculações foram feitas quando as plantas completaram oito dias após a germinação e apresentavam as folhas (primárias) com $2 / 3$ do desenvolvimento total. As plantas foram inoculadas simultaneamente com uma suspensão do patógeno, na concentração de $2.10^{4}$ uredosporos $/ \mathrm{ml}$ de água destilada, (aproximadamente $1 \mathrm{ml}$ de suspensão/planta), com o auxílio de um atomizador De Vilbiss $\mathrm{n}^{\circ} 25$. Após as inoculações as plantas foram levadas para uma câmara de nebulização a $22 \pm 1{ }^{\circ} \mathrm{C}$, onde permaneceram por períodos de 4, 8, 16, $20 \mathrm{e} 24 \mathrm{~h}$, para depois serem levadas a uma câmara climatizada com regime de luz/ escuro de $12 \mathrm{~h}$, com $22 \pm 1{ }^{\circ} \mathrm{C}$.

\section{Avaliações}

Os trabalhos foram desenvolvidos através de dois experimentos. No primeiro, foram utilizadas as cultivares Diamante Negro, Safira, Rosinha G-2 e Ouro Negro (suscetíveis), Xamego, Rio Tibagí, e Maravilha (moderadamente resistentes), além de Rudá e Corrente consideradas resistentes, segundo trabalhos conduzidos na Embrapa Arroz e Feijão (Costa et al., 1999). Neste primeiro experimento foram avaliados os efeitos dos períodos de molhamento e da cultivar na porcentagem de área foliar infetada e no número total de lesões (pústulas + necroses) por área foliar. No segundo experimento foram utilizadas as cultivares Rosinha G-2, Safira e Diamante Negro (suscetíveis), Rio Tibagí e Xamego (moderadamente resistentes), sendo determinados os períodos de incubação, de latência, e as porcentagens de lesões esporulantes (pústulas) e de lesões de suscetibilidade (pústulas maiores que $0,3 \mathrm{~mm}$ ). Os períodos de incubação e de latência foram determinados em horas, contadas desde o 
momento da inoculação até o aparecimento dos primeiros sintomas (flecks) e das primeiras pústulas, respectivamente. Estas avaliações foram feitas diariamente, pela manhã e à tarde, a partir do quinto dia após a inoculação. As contagens das lesões foram realizadas numa área de $1 \mathrm{~cm}^{2}$, em duas posições, distantes $2 \mathrm{~cm}$ do ápice e da base de cada folha. As porcentagens de área foliar infetada foram estimadas de acordo com uma escala diagramática (Embrapa, 1976). A porcentagem de área foliar infetada, o número de lesões $/ \mathrm{cm}^{2}$, as porcentagens de lesões esporulantes e de suscetibilidade, foram determinados no $12^{\circ}$ dia após a inoculação. As freqüências de lesões esporulantes e de suscetibilidade, foram estabelecidas em relação aos totais de lesões presentes (lesões necróticas e pústulas) em cada área foliar avaliada. Estas avaliações foram feitas em oito folhas primárias de plantas de diferentes vasos, num total de 16 leituras, em cada repetição.

\section{RESULTADOS E DISCUSSÃO}

\section{Área foliar infetada}

As cultivares Corrente e Rudá não apresentaram lesões em qualquer período de molhamento, mostrando possuírem altos níveis de resistência às populações do patógeno utilizadas, confirmando as informações de Costa et al.,(1999). As análises de regressão do período de molhamento (Figura 1), para os grupos suscetíveis e moderadamente resistentes, indicaram que as cultivares suscetíveis (Diamante Negro, Safira, Rosinha G-2 e Ouro Negro) apresentaram porcentagens de área foliar infetada crescentes até $20 \mathrm{~h}$, com um decréscimo após $20 \mathrm{~h}$ de molhamento. Já as cultivares com resistência moderada (Xamego, Rio Tibagí e Maravilha), apresentaram área foliar infetada crescente até com um período de $24 \mathrm{~h}$ de molhamento. $\mathrm{O}$ decréscimo na área foliar infetada observado nas cultivares suscetíveis que ocorreu após $20 \mathrm{~h}$ de molhamento, pode significar que, a partir de uma determinada concentração de pontos de infecção, as lesões que se formam primeiro, podem dificultar o desenvolvimento de outras que resultam de infecções posteriores. Os trabalhos conduzidos por Schuh (1991) mostraram que a severidade da doença causada por Cercospora kikuchii (T. Matsu \& Tomayasu) Chupp. em soja [Glycine Max (L.) Merril.] aumentou com o aumento do período de molhamento foliar sob todas as temperaturas estudadas, mas a taxa de aumento da severidade da doença, declinou com os períodos mais longos.

Todas as cultivares suscetíveis apresentaram lesões, embora poucas esporulantes (pústulas), com $4 \mathrm{~h}$ de molhamento. A análise de variância dos efeitos individuais das cultivares na área foliar infetada (Tabela 1) mostrou que, embora a cultivar suscetível Ouro Negro, tenha sido significativamente diferente da Diamante Negro também suscetível, não diferiu da cultivar Xamego, de resistência moderada. As cultivares suscetíveis apresentaram maior porcentagem de área foliar infetada que as moderadamente resistentes, como pode ser observado nas curvas de regressão
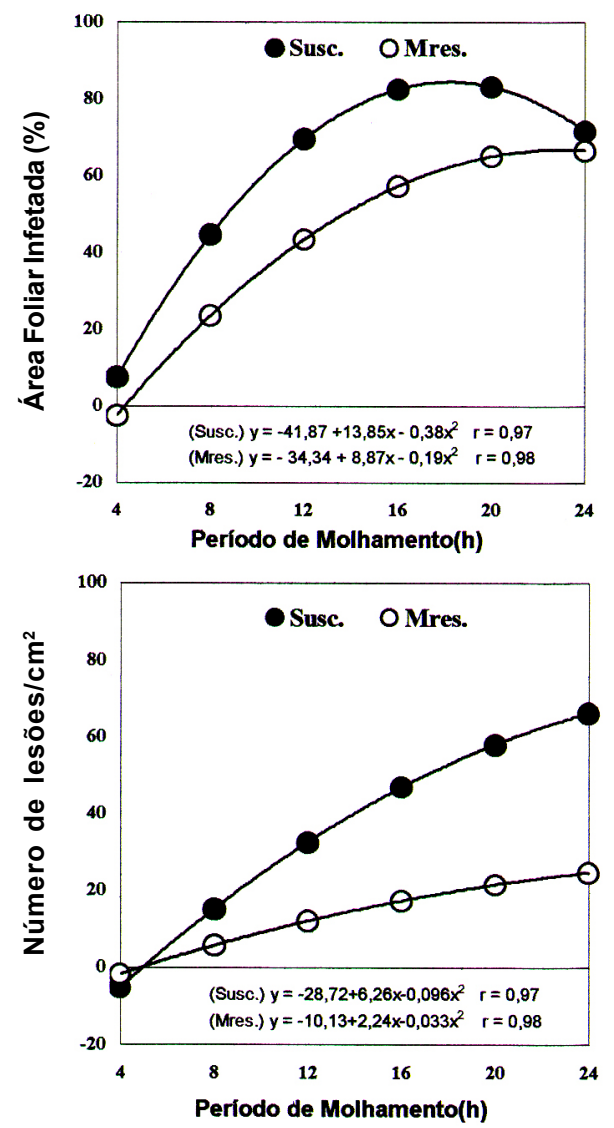

FIG. 1 -Influência do período de molhamento e da resistência genética na porcentagem de área foliar infetada e no número de lesões causadas por $\boldsymbol{U}$. appendiculatus em feijoeiro comum. Susc. = Cultivares Suscetíveis; Mres. = Cultivares moderadamente resistentes.

referentes aos dois grupos, apresentadas na Figura 1. O resultado da análise de variância permitiu constatar influência significativa do período de molhamento na porcentagem de área foliar infetada, segundo as avaliações realizadas aos 12 dias após as inoculações. Os efeitos dos períodos de molhamento na área foliar infetada indicaram que não houve diferença entre os períodos de 16,20 ou $24 \mathrm{~h}$, mas que foram diferentes dos períodos de 12,8 e $4 \mathrm{~h}$, que também diferiram entre si (Figura 1, Tabela 1). Os períodos de molhamento de 4,8 e 12 h, não se mostraram adequados, porém os períodos de 16,20 e $24 \mathrm{~h}$ foram efetivos para avaliação dos efeitos do período de molhamento na infecção e no desenvolvimento de lesões de ferrugem no feijoeiro comum, de acordo com a porcentagem de área foliar infetada.

\section{Número de lesões}

Com relação ao número de lesões $/ \mathrm{cm}^{2}$, os estudos de regressão mostraram que houve crescimento com até $24 \mathrm{~h}$ do molhamento, embora mais acentuado nas cultivares suscetíveis que nas moderadamente resistentes (Figura 1). Com relação a esta característica, as cultivares suscetíveis 
Influência da resistência e do período de molhamento na infecção...

TABELA 1 - Efeito da cultivar e do período de molhamento na porcentagem de área foliar infetada (AFI) e no número de lesões $\left(\mathrm{NL} / \mathrm{cm}^{2}\right)$ causadas por Uromyces appendiculatus em feijoeiro comum (Phaseolus vulgaris)

\begin{tabular}{lcc}
\hline \hline Cultivares & AFI (\%) & $\mathbf{N L}\left(\mathbf{c m}^{\mathbf{2}}\right)^{\mathbf{z}}$ \\
\hline Diamante Negro & $64,58 \mathrm{a}^{1}$ & $45,79 \mathrm{a}^{1}$ \\
Rosinha G-2 & $59,01 \mathrm{ab}$ & $32,69 \mathrm{~b}$ \\
Safira & $61,67 \mathrm{a}$ & $30,01 \mathrm{~b}$ \\
Ouro Negro & $54,54 \mathrm{bc}$ & $28,51 \mathrm{~b}$ \\
Xamego & $51,40 \mathrm{c}$ & $15,53 \mathrm{c}$ \\
Rio Tibagí & $36,99 \mathrm{~d}$ & $16,63 \mathrm{c}$ \\
Maravilha & $36,21 \mathrm{~d}$ & $12,26 \mathrm{c}$ \\
Rudá & $0,00 \mathrm{e}$ & $0,00 \mathrm{~d}$ \\
Corrente & $0,00 \mathrm{e}$ & $0,00 \mathrm{~d}$ \\
\hline \multicolumn{1}{c}{ Molhamento (h) } & AFI (\%) $)^{\mathbf{X}}$ & $\mathbf{N L}\left(\mathbf{c m}^{\mathbf{2}}\right)^{\mathbf{z}}$ \\
\hline \multicolumn{1}{c}{24} & $54,55 \mathrm{a}^{1}$ & $34,96 \mathrm{a}^{1}$ \\
20 & $57,11 \mathrm{a}^{1}$ & $36,33 \mathrm{a}$ \\
16 & $54,42 \mathrm{a}$ & $31,71 \mathrm{a}$ \\
12 & $43,84 \mathrm{~b}$ & $11,62 \mathrm{~b}$ \\
8 & $32,86 \mathrm{c}$ & $6,22 \mathrm{bc}$ \\
4 & $0,15 \mathrm{~d}$ & $0,11 \mathrm{c}$ \\
\hline
\end{tabular}

${ }^{1}$ Médias seguidas pela mesma letra não são significativamente diferentes pelo teste de Tukey a $5 \%$ de probabilidade

${ }^{\mathrm{x}}$ Dados transformados em arc sen $、 \mathrm{x} / 100$

${ }^{\mathrm{z}}$ Dados transformados em $\sqrt{\mathrm{x}+1}$

diferiram estatisticamente das moderadamente resistentes e das resistentes, sendo estas diferentes das moderadamente resistentes (Tabela. 1). Como no caso da área foliar infetada, não houve diferença significativa quanto ao número de lesões/ $\mathrm{cm}^{2}$, referentes a 16,20 e $24 \mathrm{~h}$ de molhamento, que por sua vez, diferiram dos períodos de 12, 8 , e $4 \mathrm{~h}$. Estes resultados sugerem que, um período de molhamento de $16 \mathrm{~h}$, sob temperatura de $22 \pm 1{ }^{\circ} \mathrm{C}$, pode ser suficiente para avaliar níveis de resistência à ferrugem em cultivares de feijoeiro, quando se utiliza o número de lesões $/ \mathrm{cm}^{2}$ área foliar, na avaliação. Webb \& Nutter (1997) concluíram que os efeitos críticos do período de molhamento e da temperatura na eficiência de infecção de $U$. striatus, agente causal da ferrugem da alfafa, ocorrem durante as primeiras $24 \mathrm{~h}$ de molhamento, após a deposição dos esporos.

Houve efeito diferenciado do período de molhamento quanto ao número de lesões por área foliar, quando foram considerados os períodos de 4,8 e $12 \mathrm{~h}$ de molhamento. Nestes períodos, o número de lesões formadas foi muito pequeno e, nestes casos, o número de lesões $/ \mathrm{cm}^{2}$, mostrou não ser um critério ideal de avaliação. Os resultados indicaram, também, a importância da padronização dos fatores que influenciam no desenvolvimento da ferrugem do feijoeiro quando se deseja avaliar determinados elementos ligados à resistência das cultivares à ferrugem.

\section{Período de incubação}

Os períodos de incubação das cultivares Rio Tibagí, Xamego (moderadamente resistentes), Diamante Negro, Rosinha G-2 e Safira (suscetíveis), avaliados no segundo experimento, indicaram diferenças, de acordo com o nível de resistência da cultivar. As cultivares suscetíveis tiveram períodos de incubação mais curtos que as moderadamente resistentes, sob todos os períodos de molhamento estudados. Os períodos de incubação, a partir de $16 \mathrm{~h}$ de molhamento, estabilizaram-se em 5,75 dias, nas cultivares suscetíveis, e em 6,75 dias, nas cultivares de resistência moderada (Figura 2). Apenas a cultivar Rio Tibagí não apresentou flecks quando o período de molhamento foi de apenas $4 \mathrm{~h}$. Com este período de molhamento, a cultivar Xamego teve um período de incubação de 6,75 dias, enquanto as cultivares suscetíveis apresentaram períodos de 6,0 dias (Safira) e 6,2 dias (Rosinha G-2 e Diamante Negro). A sarna da nogueira, causada por C. caryigenum, não teve o período de incubação influenciado pelo período de molhamento (Turechek \& Stevenson, 1998). No entanto, segundo análise logística de regressão estabelecida pelos mesmos autores, a probabilidade de uma folha de nogueira ser infetada por C. caryigenum foi maior na cultivar suscetível, aumentando a probabilidade, com o aumento do período de molhamento foliar.

\section{Período de latência}

Os dados não parecem coerentes, já que se observou a presença de pústulas com 12 e $16 \mathrm{~h}$ de molhamento e não com 20 e 24 h, no caso da cultivar Rio Tibagí, ou presença de pústulas com 16 e $20 \mathrm{~h}$ e não com $24 \mathrm{~h}$, no caso da Xamego (Figura 2). Este resultado pode ser entendido se levarmos em consideração ser muito pequeno o número de pústulas nas cultivares com resistência moderada e, em conseqüência, de presença esporádica dentro das áreas de avaliação de $1 \mathrm{~cm}^{2}$. Deduz-se diante deste fato, que o número de lesões $/ \mathrm{cm}^{2}$ não representa o método mais adequado, principalmente quando se trata de cultivares não suscetíveis. Mesmo com estes resultados, ficou evidente que o período de latência foi mais longo nas cultivares moderadamente resistentes que nas cultivares suscetíveis. A cultivar Safira, que apresentou o menor período de incubação com $4 \mathrm{~h}$ de molhamento, apresentou, também, o período de latência mais curto sob este período, ou seja, 8,2 dias. Embora Bergamin Filho \& Amorim (1996) tenham afirmado que a latência é válida como critério de seleção de variedades resistentes para patossistemas onde a expansão das lesões é insignificante, os resultados deste trabalho mostraram que períodos de incubação e de latência não parecem ser úteis na separação de níveis de resistência entre as cultivares suscetíveis, mas mostraram-se importantes no agrupamento diferenciado entre cultivares suscetíveis e com resistência moderada.

Nas cultivares resistentes, onde o período de latência é mais longo, muitos flecks tornam-se inibidos antes da fase de esporulação. No caso específico deste trabalho, não houve esporulação nas cultivares resistentes.

\section{Lesões esporulantes e de suscetibilidade}

O menor número de lesões/área foliar, obtido no segundo experimento, facilitou a quantificação das lesões esporulantes e de suscetibilidade. Um número elevado de lesões/área foliar permitiria que uma lesão dificultasse o pleno 

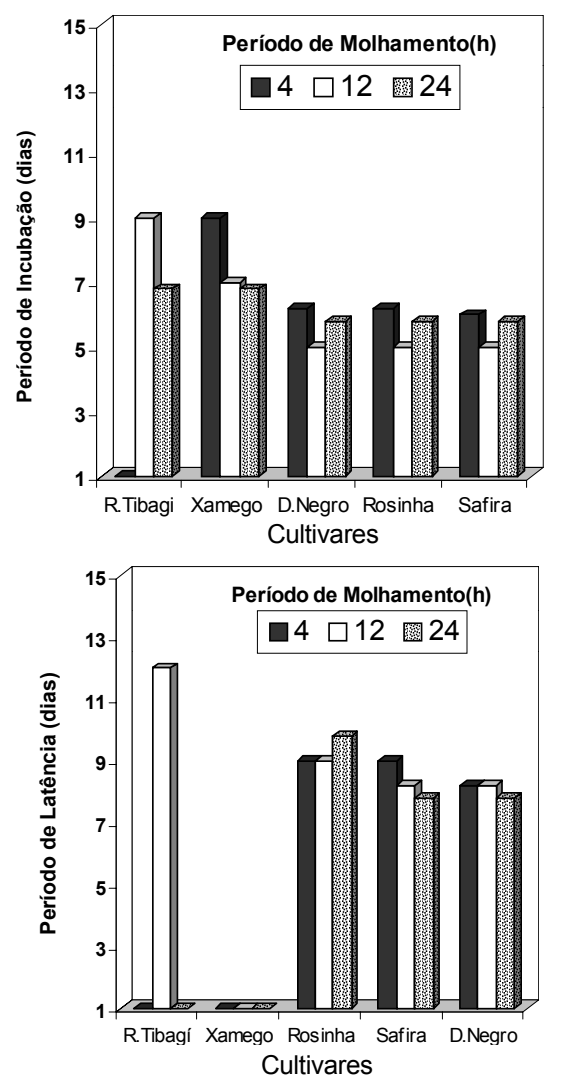

FIG. 2 - Influência do período de molhamento foliar e da resistência genética nos períodos de incubação e de latência de Uromyces appendiculatus em feijoeiro comum.

desenvolvimento de outra que estivesse muito próxima, interferindo nos resultados de avaliações envolvendo o tamanho da lesão. A porcentagem de lesões esporulantes ou lesões de suscetibilidade foram as características que melhor diferenciaram as cultivares suscetíveis daquelas com resistência moderada, ou que mais claramente agruparam as cultivares, de acordo com os níveis de resistência estudados neste experimento (Figura 3 e Tabela 2). Dentro de cada grupo, as cultivares suscetíveis ou com resistência moderada não apresentaram diferença significativa quanto às porcentagens de lesões esporulantes e lesões de suscetibilidade (Tabela 2).

O número de lesões esporulantes não foi um critério muito adequado para avaliar o efeito do período de molhamento na infecção de $U$. appendiculatus em feijoeiro. $\mathrm{O}$ efeito diferenciado do período de molhamento quanto ao número de lesões por área foliar, quando foram considerados os períodos de 4,8 e $12 \mathrm{~h}$ de molhamento, influenciou igualmente nestes resultados. Nestes períodos, o número de lesões formado foi muito pequeno e, em conseqüência, o número de lesões $/ \mathrm{cm}^{2}$, o que tornou de pouca validade a utilização destes valores como critério de avaliação. Há necessidade de novas pesquisas que visem o aprimoramento nas técnicas de avaliação da resistência genética à ferrugem
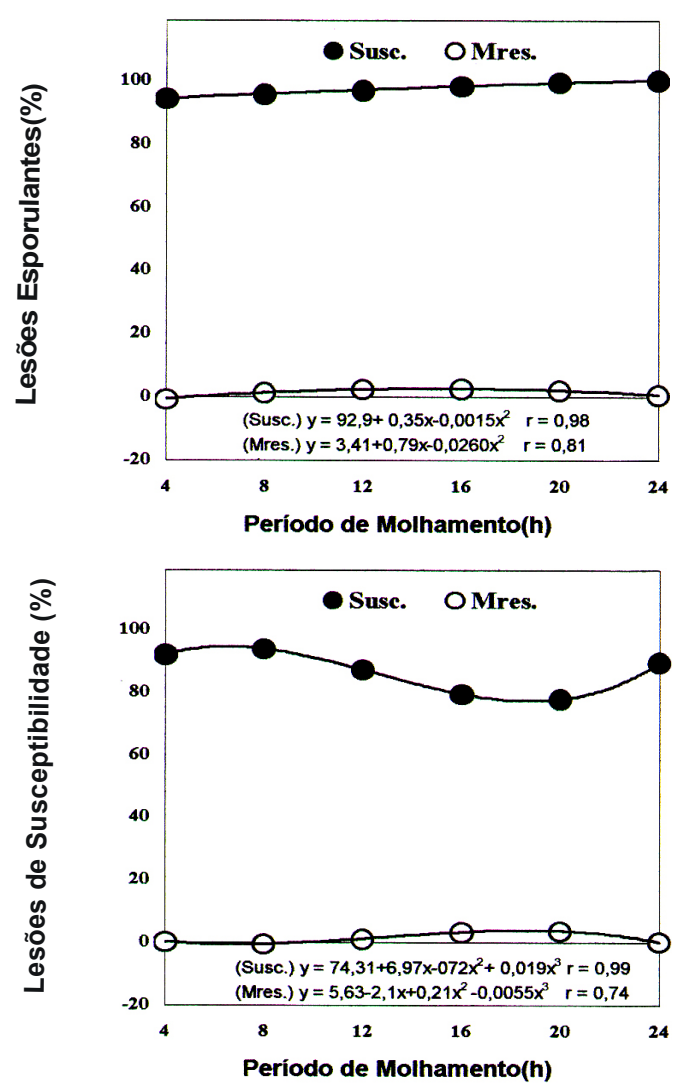

FIG. 3 - Influência do período de molhamento e da resistência genética na porcentagem de lesões esporulantes e de suscetibilidade causadas por $U$. appendiculatus em feijoeiro comum. Susc. $=$ Cultivares suscetíveis. Mres. $=$ Cultivares moderadamente resistentes

TABELA 2 - Efeito da cultivar e do período de molhamento na porcentagem de lesões esporulantes (pústulas), e porcentagem de lesões de suscetibilidade (pústulas maiores que 0,3 $\mathrm{mm}$ ), causadas por Uromyces appendiculatus em feijoeiro comum (Phaseolus vulgaris).

\begin{tabular}{lcc}
\hline \hline Cultivar & LE $^{\mathbf{x}}$ & $\mathbf{L S}^{\mathbf{x}}$ \\
\hline Diamante Negro & $97,77 \mathrm{a}^{1}$ & $84,83 \mathrm{a}^{1}$ \\
Safira & $95,15 \mathrm{a}$ & $82,79 \mathrm{a}$ \\
Rosinha G-2 & $95,91 \mathrm{a}$ & $86,91 \mathrm{a}$ \\
Xamego & $0,37 \mathrm{~b}$ & $0,44 \mathrm{~b}$ \\
Rio Tibagí & $1,23 \mathrm{~b}$ & $1,07 \mathrm{~b}$ \\
\hline Molhamento (h) & & \\
\hline 24 & $60,00 \mathrm{a}^{1}$ & $51,16 \mathrm{ab}$ \\
20 & $59,97 \mathrm{a}$ & $46,32 \mathrm{~b}$ \\
16 & $59,29 \mathrm{ab}$ & $48,89 \mathrm{ab}$ \\
12 & $58,27 \mathrm{ab}$ & $52,34 \mathrm{ab}$ \\
8 & $54,19 \mathrm{~b}$ & $53,24 \mathrm{ab}$ \\
4 & $56,80 \mathrm{ab}$ & $55,24 \mathrm{a}$ \\
\hline
\end{tabular}

${ }^{1}$ Médias seguidas pela mesma letra não são significativamente diferentes pelo teste de Tukey a $5 \%$ de probabilidade.

${ }^{x}$ Dados transformados em arc sen 、 $\mathrm{x} / 100$

LE $=$ Lesões esporulantes (pústulas).

LS $=$ Lesões de suscetibilidade (pústulas maiores que $0,3 \mathrm{~mm}$ ). 
do feijoeiro, bem como a adequação dos fatores de ambiente onde se desenvolve a pesquisa à epidemiologia da doença para que o alcance das informações obtidas seja o maior, quanto possível.

\section{REFERÊNCIAS BIBLIOGRÁFICAS}

BERGAMIN FILHO, A. \& AMORIM, L. Doenças de plantas tropicais: epidemiologia e controle econômico. São Paulo. Agronômica Ceres. 1996.

DAVISON, A.D. \& VAUGHAN, E.K. A simplified method for identification of races of Uromyces phaseoli var. phaseoli. Phytopathology 53:456-459. 1963.

DAVISON, A.D. \& VAUGHAN, E.K. Effect of uredospore concentration on determination of races of Uromyces phaseoli var. phaseoli. Phytopathology 154:336-338. 1964.

EMBRAPA. Centro Nacional de Pesquisa de Arroz e Feijão (Goiânia, GO). Manual de Métodos de Pesquisa em Feijão: Primeira Aproximação. 2.ed. Goiânia. 1976.

FALEIRO, F.G., VINHADELLI, W.S., RAGAGNIN, V.A., ZAMBOLIM, L., PAULA JUNIOR, T.J., MOREIRA, M.A. \& BARROS, E.G. Identificação de raças fisiológicas de Uromyces appendiculatus no Estado de Minas Gerais, Brasil. Fitopatologia Brasileira 24:166169. 1999.

HARTER, L.L. Studies on bean rust caused by Uromyces phaseoli typica. Journal of Agricultural Research 50:737753. 1935.

JONES, A.L. Role of the wet weather in predicting foliar diseases. In: LEONARD, K.J. \& FRY, W.E. (Eds.). Plant
Disease Epidemiology: Population Dynamics and Management. New York. Macmillan Publishing Co. 1986. pp.87-100.

MORA, N.O.A., VIEIRA, C. \& ZAMBOLIM, L. Variedades diferenciadoras de feijão para identificação de raças fisiológicas de Uromyces phaseoli var. typica Arth. Revista Ceres 39:391-404. 1992.

PARLEVLIET, J.E. Components of resistance that reduce the rate of epidemic development. Annual Review of Phytopathology 17:203-222. 1979.

SOUZA, R. de C.M.D., RIOS, G.P. \& FRANCO, L.G. Reação de genótipos de feijoeiro à ferrugem e à mancha angular. In: Resumos expandidos, $6^{\text {a }}$ Reunião Nacional de Pesquisa de Feijão, Salvador, BA. 1999. Santo Antônio de Goiás. Embrapa Arroz e Feijão, 1999. pp.226-227.

STAVELY, J.R. Pathogenic specialization in Uromyces phaseoli in the United States and rust resistance in beans. Plant Disease 68:95-99. 1984.

THAKUR, R.P., RAO, V.P. \& KING, S.B. Influence of temperature and wetness duration on infection of pearl millet by Claviceps fusiformis. Phytopathology 81:835838. 1991.

TURECHECK, W.W. \& STEVENSON, K.L. Effects of host resistance, temperature, leaf wetness, and leaf age on infection and lesion development of pecan Scab. Phytopathology 88:1294-1301. 1998.

WEBB, D.H. \& NUTTER JR., F.W. Effects of leaf wetness duration and temperature on infection efficiency, latent period, and rate of pustule appearance of rust in alfafa. Phytopathology 87:946-950. 1997. 